Case Report

J Exp Clin Med

2021; 38(4): 669-671

doi: $10.52142 /$ omujecm. 38.4 .45

\title{
Coexistence of human immuno deficiency virus, diabetes mellitus, epididymal cysts, and Fournier's gangrene: A case report
}

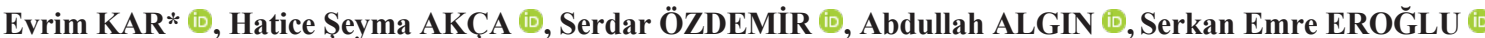

Department of Emergency Medicine, Ümraniye Education and Research Hospital, University of Health Sciences, Istanbul, Turkey

Received: $12.02 .2021 \quad \bullet \quad$ Accepted/Published Online: 17.02.2021 • Final Version: 30.08 .2021

\begin{abstract}
Fournier's gangrene (FG) is a form of necrotizing fasciitis that is localized in the external genital organs and perianal region and causes skin and subcutaneous tissue gangrene. The clinical picture may vary depending on the patient's comorbidities and the extent of infection; Many predisposing conditions such as immunodeficiency, diabetes, alcoholism encourage the spread of the infection. In this case report, we highlighted the importance of emergency debridement in patients with multiple comorbidities by presenting the Fournier's Gangrene case in a 57-year-old immunosuppressive male patient with cystic lesions in the epididymis, with a history of hypertension, coronary artery disease, diabetes, HIV (human immunodeficiency virus) and a history of bipolar disorder. The patient, who was operated on for debridement by the urology, was given $1 \times 500 \mathrm{mg}$ daptomycin, $3 \times 1 \mathrm{~g}$ meropenem, 3x450mg clindamycin IV treatment. The patient was discharged with full recovery after 17 days of hospitalization. Clinical suspicion in Fournier's gangrene cases, early surgical debridement, and extended-spectrum anti biotherapy are important. with rapid diagnosis and treatment in patients with improvement can also be seen in patients with comorbidities.
\end{abstract}

Keywords: Fournier's gangrene, debridement, HIV, epididymal cysts

\section{Introduction}

Fournier's gangrene (FG) is a specific form of necrotizing fasciitis that is localized in the external genital organs and perianal region, causing skin and subcutaneous tissue gangrene (1). It is usually polymicrobial (2). The most common microorganisms isolated are Escherichia coli, Klebsiella pneumoniae, Bacteroides fragilis and Staphylococcus aureus (3).

The clinical characteristics may vary depending on the patient's comorbidities and the extent of infection; many predisposing conditions such as immunodeficiency, diabetes, and alcoholism encourage the spread of the infection, and systemic infection symptoms such as high fever and chills can be seen as well as septic shock and multiple organ failure. It is a life-threatening disease and has a high mortality rate (2). Its treatment consists of hemodynamic resuscitation, aggressive surgical debridement, and broad-spectrum antibiotics (3). In this case report, it is aimed to present a patient with epididymal cysts, diabetes mellitus, and human immune deficiency virus (HIV) infection who was admitted to the emergency department with Fournier gangrene.

\section{Case report}

A 57-year-old male patient was admitted to the emergency room with complaints of swelling and pain in the testicles. He had a history of swelling, pain, and discharge in the testicles for 5 days. It was learned that the patient, who applied to another hospital earlier, was evaluated as a scrotal abscess, and applied to us. It was learned that there were cystic lesions ( $2 \mathrm{~cm}$ on the right and $42 \mathrm{~mm}$ on the left) in the previously known bilateral epididymis.

It was learned that he had diabetes mellitus, hypertension, coronary artery disease, HIV (human immunodeficiency virus) history and bipolar disorder in his medical history. The drugs he used were olanzapine $2.5 \mathrm{mg}$, metoprolol $50 \mathrm{mg}$, sertraline $50 \mathrm{mg}$, quetiapine $50 \mathrm{mg}$, trimetazidine dihydrochloride $35 \mathrm{mg}$, metformin $1000 \mathrm{mg}$, insulin glargine $10 \mathrm{U}$, acetylsalicylic acid $100 \mathrm{mg}$, elvitegravir + cobicistat + emtricitabine + tenofovir combination. The admission fever was: $36.2^{\circ} \mathrm{C}$, pulse: $85 / \mathrm{min}$, blood pressure: $85 / 45 \mathrm{mmhg}$, respiratory rate: 20/min, $\mathrm{SpO}_{2}: 97 \%$. The patient was conscious, cooperatively oriented, GCS (Glasgow coma scale) was 15 , and no pathological finding was found in his neurological examination. In scrotal examination, there was subcutaneous edema, redness, and warmth, as well as tenderness with palpation in the left epididymis and testicle (Fig. 1). In ultrasonographic imaging, testicular parenchymal echo structures and blood supply were homogeneous, and an anechoic cystic lesion with a diameter of $4.5 \mathrm{~mm}$ at the left rete level and a $51 \times 37 \mathrm{~mm}$ blob thin septation in the left scrotal sac at the epididymis level were present. Left epididymis increased in size, parenchyma echo was heterogeneous, scrotum skin and subcutaneous fatty tissue were edematous. There was an $18 \times 22 \mathrm{~mm}$ anechoic cyst in the right epididymis. 

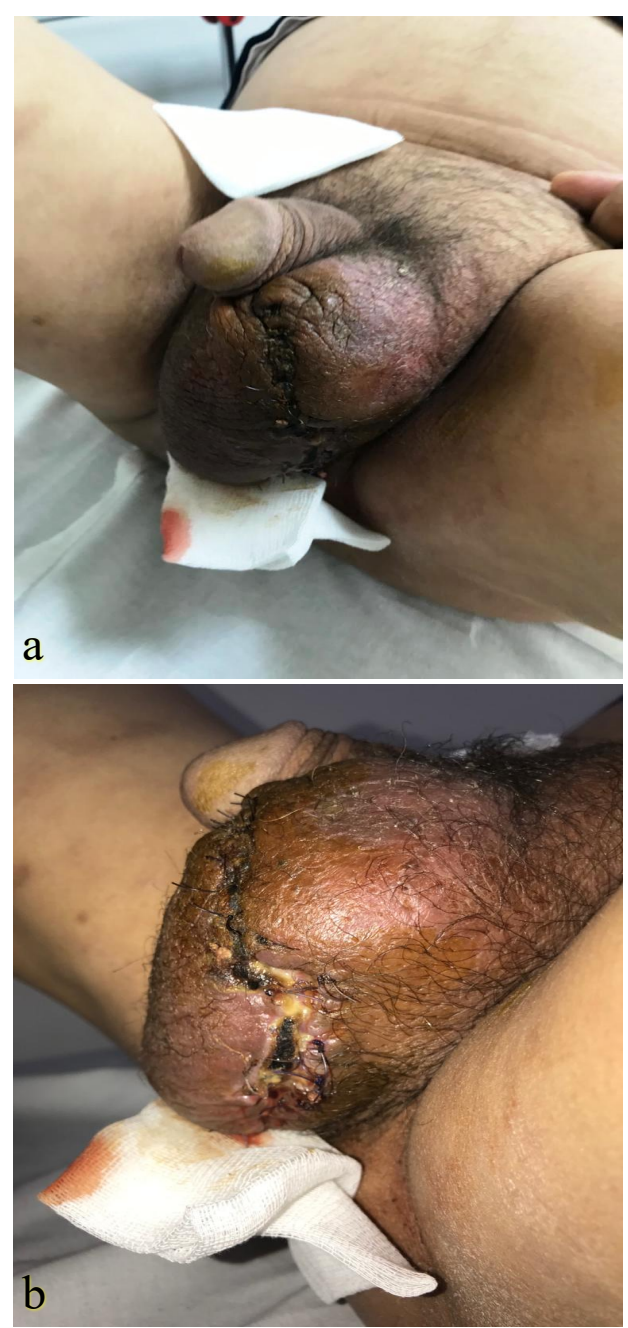

Fig. 1. Subcutaneous edema and redness in the scrotum $(a, b)$

In laboratory tests, hemoglobin was: $12.6 \mathrm{~g} / \mathrm{dl}$, htc (hematocrit): $38.1 \%$, thrombocyte: $212.000 \mathrm{u} / \mathrm{L}$, leukocyte:14910 u/L (Cutoff: 4.000-10.000), neutrophil:11890 u / L (Cut off: 2.000-7.000), neutrophil (\%): 79.8\%, glucose: $629 \mathrm{mg} / \mathrm{dl}$, Crp (C-Reactive Protein): 27.5 $\mathrm{mg} / \mathrm{dL}$ (Cut off: 0.0-0.5), and liver and kidney function tests were normal. During the follow-up of the patient, blood glucose regulation was provided in consultation with internal medicine. (Control blood glucose was: $183 \mathrm{mg} / \mathrm{dl}$.) The patient, who was operated on for debridement by the urology, was given $1 \times 500 \mathrm{mg}$ daptomycin, $3 \times 1 \mathrm{~g}$ meropenem, $3 \times 450 \mathrm{mg}$ clindamycin IV treatment. The patient was discharged with full recovery after 17 days of hospitalization.

\section{Discussion}

Fournier's gangrene (FG), polymicrobial necrotizing fasciitis, is a rare, life-threatening soft tissue infection that affects the reproductive organs and the perineum with a high mortality rate (4). The incidence of the disease is approximately 1.6-3 $/ 100,000$, varying according to various studies, and it is 10 times more common in males (5). Most patient populations have an underlying systemic disease, such as diabetes mellitus, alcoholism, obesity, peripheral vascular disease, perianal disease, urethral stricture, trauma, and immunosuppression, which increase susceptibility to necrotic fasciitis (4). Smith et al. determined that chronic alcoholism is the most common accompanying disease to Fournier gangrene (6). HIV is the most important concomitant disease in some studies in Africa $(7,8)$. In a study conducted by Sockkalingam et al., It was observed that FG significantly accompanied HIV infection. (9). In the study of Başoğlu et al., the most related comorbidity with FG was seen as diabetes mellitus (10). Our patient had both diabetes mellitus and HIV infection.

In addition to comorbidities, accompanying diseases have also taken their place in the etiology of Fournier gangrene. Unalp et al., found in their study that anorectal abscess and primary scrotal abscess accompany Fournier gangrene (11). In a case report reported by Cook et al., epididymal cysts were found to be present along with epididymis (12). In addition, there is an epididymal cyst without epididymitis in the case reported by Islam et al. (5). While more than one epididymal cyst was detected in our study; there was no sign of epididymitis. Since epidermal cysts on the scrotum are painless, they are ignored by patients. It is very difficult to determine the relationship between epididymal cysts and treatment response or mortality, considering that they can be detected when the diagnosis of scrotal abscess or gangrene and that comorbidities are more prominent in patients with FG. The presence of epididymal cysts in our patient is insufficient in determining prognosis due to the presence of concomitant HIV infection and diabetes mellitus. When the scrotal skin is infected, the infected part should be debrided extensively to prevent Fournier gangrene and septicemia (13). Recently, while a decrease in mortality rates can be expected due to advances in Fournier etiology and management, a meta-analysis showed that there was no decrease in mortality, but also comorbidities and increasing age were found to be effective in mortality. While the most common cause of death was sepsis; the second reason has been recorded as multiple organ failure (3), mortality was reported at a rate of $11.8 \%$ (9), $8.8 \%$ (14). Radcliffe et al. reported that FG mortality is $20 \%$ (15). The aggressive use of extended-spectrum antibiotics can improve outcomes and reduce mortality. Surgical debridement is the key point in FG management (3). The effect of treatment on mortality in FG has also taken its place in the literature. Yoshino et al. In his study, a patient with Fournier gangrene diagnosed with rectal cancer underwent emergency diverting colostomy and intensive debridement, and the recovery period reached 108 days (16). Even with extended-spectrum antibiotics and wide exudation debridement, the mortality rate reaches up to $45 \%$. (15). In addition, according to the study of Carrell et al., mortality was $100 \%$ in patients who did not receive debridement; in debridement patients, mortality is $6 \%(16)$. Although it is not known exactly whether debridement or broad-spectrum antibiotic treatment is more effective in determining the prognosis, our patient was discharged after 17 days with early debridement and treatment follow-up. The low incidence of 
FG has led to more retrospective study preferences. Thus, it should be kept in mind that the clinical follow-up and history of the patient may be insufficient. In addition, most of the patients are elderly. In addition, we think that case reports will have an important place in the follow-up of recovery times and patient prognosis in rare cases. The effect of treatment on mortality should be evaluated together with comorbidities. We think that our patient, who had cystic lesions in the epididymis in addition to diabetes mellitus and HIV and recovered, will contribute to the literature.

With rapid diagnosis and treatment in Fournier's gangrene cases, patients with multiple comorbidities can also improve. In addition, epidermal emergency physicians should be aware that infections in the perianal region can rapidly progress to the fournier gangrene, especially in elderly patients with comorbidities.

\section{Conflict of interest}

None to declare.

\section{Acknowledgments}

None to declare.

\section{References}

1.Chernyadyev SA, Ufimtseva MA, Vishnevskaya IF, Bochkarev YM, Ushakov AA, Beresneva TA, et al. Fournier's Gangrene: Literature Review and Clinical Cases. Urol Int. 2018; 101(1): 917. https://doi.org/10.1159/000490108.

2.Zhang N, Yu X, Zhang K, Liu T. A retrospective case series of Fournier's gangrene: necrotizing fasciitis in perineum and perianal region. BMC Surg. 2020; 20(1): 1-8. https://doi.org/10.1186/s12893-020-00916-3.

3.El-Qushayri AE, Khalaf KM, Dahy A, Mahmoud AR, Benmelouka AY, Ghozy S, et al. Fournier's gangrene mortality: A 17-year systematic review and meta-analysis. Int J Infect Dis. 2020; 92 : 218-25. https://doi.org/10.1016/j.ijid.2019.12.030.

4. Taylor GM, Hess DV. Fournier gangrene: A rare case of necrotizing fasciitis of the entire right hemi-pelvis in a diabetic female. Oxf Med Case Reports. 2018; 48-9. https://doi.org/10.1093/omcr/omx094.
5.İslam MM, Aksel G. Diyabetus mellitus ve fournier gangreni birlikteliği: Olgu Sunumu. Anatolian J Emerg Med. 2019; 2(1): 3033.

6. Smith GL, Bunker CB, Dinneen MD. Fournier's gangrene. Br J Urol. 1998; 81(3): 347-55.

7.Elem B, Ranjan P. Impact of immunodeficiencyvirus (HIV) on Fournier's gangrene: Observations in Zambia. Ann R Coll Surg Engl. 1995; 77(4): 283-6.

8.Ngugi P, Magoha G, Nyaga P. Fournier'sgangrene in the HIV era. Afr Health Sci. 2014; 14(4):1063- 8.

9.Sockkalingam, VS, Subburayan E, Velu E, Rajashekar ST, Swamy AM. Fournier's gangrene: Prospective study of 34 patients in South Indian population and treatment strategies. Pan Afr Med J. 2018; 31: 1-8. https://doi.org/10.11604/pamj.2018.31.110.15495.

10. Unalp HR, Kamer E, Derici H, Atahan K, Balcı U, Demirdöven $\mathrm{C}$, et al. Fournier's gangrene: Evaluation of 68 patients and analysis of prognostic variables. J Postgrad Med. 2008; 54(2):102-5.

11. Cook BP, Verdone C, Ricchiuti D. Scrotal emphysema with characteristics of Fournier's gangrene in a community setting. Urol Case Reports. 2020; 33:101345. https://doi.org/10.1016/j.eucr.2020.101345.

12. Mardi K. Multiple scrotal epidermal cysts: A rarecasereport. J Clin Sci. 2014; 11:20-1.

13. Basoglu M, Ozbey I, Atamanalp SS, Yildirgan MI, Aydinli B, Polat O, et al. Management of Fournier's gangrene: Review of 45 cases. Surg Today. 2007; 37(7): 558-63. https://doi.org/10.1007/s00595-006-3391-6

14. Radcliffe RS, Khan MA. Mortality associated with Fournier's gangrene remains unchanged over 25 years. BJU Int. 2020; 125(4): 610-616. https://doi.org/10.1111/bju.14998

15. Yoshino Y, Funahashi K, Okada R, Miura Y, Suzuki T, Koda T, et al. Severe Fournier's gangrene in a patient with rectal cancer: Case report and literature review. World J Surg Onc. 2016; 14(1): 1-5. https://doi.org/10.1186/s12957-016-0989-z.

16. Carroll PR, Cattolica EV, Furzan KW. Necrotising soft tissue infection of the perineum and genitalia: Aetiology and early reconstruction. West J Med. 1986; 144: 174-8. 